\title{
Nurse Attitude-Related Barriers to Effective Control of Cancer Pain among Iranian Nurses
}

\author{
Adel Sadeghy ${ }^{1}$, Robab Mohamadian ${ }^{2}$,Azad Rahmani*, Hussein Fizollah-zadeh ${ }^{1}$, \\ Franak Jabarzadeh ${ }^{1}$, Arman Azadi ${ }^{4}$, Hussein Rostami ${ }^{5}$
}

\begin{abstract}
Background: Many cancer patients still experience pain worldwide. There are many barriers for effective control of cancer pain and many of these are related to health care providers. There is a need for further investigation of these barriers. The aim of this study was to investigate nurse-related barriers to control of cancer pain among Iranian nurses. Materials and Methods: In this descriptive study 49 nurses from two hospitals affiliated to Tabriz and Ardebil Universities of Medical Sciences participated using a census sampling method. A demographic and profession related checklist and Barriers Questionnaire II (BQ-II) were used for data collection. Results: The results showed negative attitudes of participants regarding control of cancer pain. Participants believed that cancer pain medications do not manage cancer pain at acceptable levels; patients may become addicted by using these drugs; cancer pain medications have many uncontrollable effects; and controlling cancer pain may distract the physicians from treating disease. Conclusions: Iranian nurses have negative attitudes toward pain control in cancer patients especially about effectiveness of pain medication and their side effects. Educational intervention to reduce these misconceptions is needed.
\end{abstract}

Keywords: Cancer - pain - cancer pain - nurses - barriers - attitude - Iran

Asian Pac J Cancer Prev, 17 (4), 2141-2144

\section{Introduction}

The number of cancer patients has increased in recent decades (van der Eerden et al., 2014). As the chemotherapy and other cancer treatments become aggressive, the number of advanced patients increases, and the prevalence of patients' signs and symptoms increase (Burton and Cleeland, 2001). Cancer therapy makes many adverse symptoms for patients such as nausea, emesis, pain, fatigue, distractibility, and poor memory. These symptoms can impair patient quality of life (Dantzer et al., 2012).

Pain is one of a major symptom in cancer patients (Macfarlane et al., 2012). The result of a systematic review by Deandrea et al. (2008) showed that in $50 \%$ of cases the pain of cancer patients is undertreated (Deandrea et al., 2008). The results of one systematic review showed that $53 \%$ of cancer patients in at all disease stages experiencing pain (van den Beuken-van Everdingen et al., 2007).

It should be noted that some studies from Middle East also showed that many of cancer patients experiences untreated cancer pain. For example a study from Turkey showed that $20.4 \%$ cancer patients were not receiving pain treatment (Aslan et al., 2011). As another example, another study reported that Jordanian cancer patients were experiencing high levels of pain, which was undertreated (Al Qadire et al., 2013).

It should be noted that cancer pain has many physiological and psychological outcomes for cancer patients (Marcus, 2011). The results of a systematic review showed that pain interact with activities of daily living, work and work efficiency, and reduced quality and quantity of life in cancer patients. One the other hand, this review showed that effective pain therapy resulted in improvements in fatigue, sleep, depression, quality of life, and work in these patients (Andrew et al., 2014).

Unfortunately, increased prevalence of cancer pain has been associated with inadequate pain control (Mishra et al., 2009). It should be noted that many advanced cancer patients depend on healthcare providers for assessment of their symptom, including cancer pain (Laugsand et al., 2010). With the purpose of improve the management of pain, all healthcare professionals, and included nurses, should have sufficient knowledge regarding pain management and ware of pain management (Arslan et al., 2014). In this regard, the results of an Iranian study showed that knowledge deficit is an important pain management barrier among Iranian physicians (Eftekhar et al., 2007).

The results of previous studies showed that there

\footnotetext{
${ }^{1}$ Medical-Surgical Department, Nursing and Midwifery Faculty, ${ }^{3}$ Hematology and Oncology Research Center, Tabriz University of Medical Sciences, Tabriz, ${ }^{2}$ Department of Nursing, Islamic Azad University, Maraghe Branch, ${ }^{5}$ Community Health Nursing Department, Nursing Faculty, Maraghe University of Medical Sciences, Maraghe, ${ }^{4}$ Department of Nursing, Ilam University of Medical Sciences, Ilam, Iran*For correspondence: azad.rahmani@yahoo.com
} 
are many barriers for cancer pain management. These barriers many are classified as health care providersrelated barriers, patient-related barriers, and society- and tradition-related barriers as well as government regulations (Fazeny et al., 2000; Chang et al., 2002; Potter et al., 2003; Oldenmenger et al., 2009). So, nurses are one of the main health care providers for assessment and management of cancer pain and the results of some studies showed that a many nursing-related barriers to cancer pain management are exist and there is a need for further studies to address these barriers (Howell et al., 2000; Al Khalaileh and Al Qadire, 2012). In a wide review of related literature there was no related studies investigated the nurses - related barriers for cancer pain in Iranian health care system. So, the aim of this study was to investigate the nurses - related barriers for control of cancer pain among Iranian nurses.

\section{Materials and Methods}

This descriptive study conducted in two hospitals affiliated to Tabriz University of Medical Sciences and Ardebil University of Medical Sciences, Iran. These hospitals are main centers for treatments of cancer patients in East Azerbaijan and Ardebil Provinces in northeast of Iran.

The study population was consisted of all nurses who working in study setting during the sampling. Inclusion criteria for these nurses were including: having BS degree in nursing and at least one year experience of caring of cancer patients. All nurses who met these criteria were 64 nurses and so; all of them were invited to participate in the study. Finally the data of 49 nurses were collected.

The study instrument consisted of two main parts. The first part was a checklist that investigated some demographic and profession-related characteristic of participants. The second part was the Barriers Questionnaire II (BQ-II). This questionnaire was developed to assess barriers to effective pain management. It consists of 27 questions about patients' barriers to pain management. Each question scored from 1 (1 agree at all) to 6 (do not agree at all) (Gunnarsdottir et al., 2002).

For using in present study, the BQ-II was translated into Persian and then back translated. The scale face and content validity were assessed and verified by the expert panel constituted ten faculty members affiliated to Tabriz University of Medical Sciences and some minor changes were applied. The final version of the questionnaire was tested for reliability in a pilot study involving 18 cancer patients. Cronbach-Alpha coefficient value for BQ-II was 0.91 .

For data collection, the research proposal was approved by Regional Ethics Committee at Tabriz University of Medical Sciences. Then, the list of all nurses who met the research inclusion criteria was obtained from the nursing offices of selected hospitals. All of the nurses were contacted in different working shifts and invited to participate in the study. The aims and methods of the study were explained for all nurses and informed consent was obtained from all of them. The nurses were asked to fill out the questionnaires in the same shift during their rest time. But, if wanted, the questionnaires gave back from nurses in their next working shifts.

Statistical analysis was conducted by using SPSS statistical software (version 13). Frequency, percentage, mean, and standard deviation were used for describe demographic and profession related characteristics and response of nurses to BQ-II.

\section{Results}

Some demographic and profession related characteristics of participants is reported in table 1. As evident in this table most of nurses are female, married, with a BS degree in nursing. Also, most of participants have a previous history of pain.

The responses of nurses to all items of BQ-II are reported in table two. The analysis of items showed that participants have many negative perceptions regarding control of cancer pain. First, in three items (items 1,8,21) regarding the effect of medications on controlling cancer pain participants had low negative attitude regarding exact effect of cancer pain medications. Second, in two items regarding possibility of be addicted by using pain medications (items 2,9,16) participants strongly believed that patients get addicted to pain medicine easily. Third, in 12 items $(3,4,5,6,7,10,13,14,18,19,20,25)$ nurses reported moderate attitude toward side effects of cancer pain. Fourth, in two items (11 and 22) participants believed that reporting cancer pain indicate the weakness of patients. Fifth, in four items $(12,23,24,27)$ participants believed that it is better that physician focus on disease instead of pain and reports of pain may distract the physicians from

Table 1. Demographic and Profession Related Characteristics of Participants

\begin{tabular}{|c|c|c|c|}
\hline Variable & Groups & Frequency & Percent \\
\hline \multirow{2}{*}{ Sex } & Male & 4 & 10.2 \\
\hline & Female & 44 & 89.8 \\
\hline \multirow{3}{*}{ Education } & $\mathrm{BS}$ in nursing & 78 & 90.7 \\
\hline & MS in nursing & 8 & 9.3 \\
\hline & Married & 40 & 81.6 \\
\hline \multirow{2}{*}{ Marital status } & Single & 9 & 18.4 \\
\hline & Widow $\backslash$ divorced & 0 & 0 \\
\hline \multirow{2}{*}{ Previous history of pain } & Yes & 30 & 61.2 \\
\hline & No & 19 & 38.8 \\
\hline Age in years, mean (SD) & $32.14(9.59)$ & & \\
\hline Work experience in years, mean (SD) & $6.24(2.14)$ & & \\
\hline
\end{tabular}


Table 2. The response of Participants to All Items of Barriers Questionnaire II

\begin{tabular}{lcc}
\hline \multicolumn{1}{c}{ Items } & Mean & SD \\
\hline 1. Pain medicine can really control pain & 2.59 & 0.83 \\
2. People get addicted to pain medicine easily & 1.95 & 0.99 \\
3. Vertigo caused by pain medications is not controllable easily & 3.69 & 1.04 \\
4. Pain medications weaken the immune system & 3.48 & 1.52 \\
5. Confusion caused by pain medications cannot be controlled & 3.69 & 1.04 \\
6. Pain medication can weaken the body & 4.87 & 0.9 \\
7. Taking pain medications may result in failure to recognize the pain in the body & 2.87 & 1.11 \\
8. Pain medication can control cancer pain completely & 2.53 & 0.93 \\
9. Many patients become addicted by using pain medication & 2.42 & 1.2 \\
10. Nausea induced by pain medications is not controllable & 4.26 & 1.23 \\
11. It is important to be so strong that do not talk about pain of the disease & 2.93 & 1.86 \\
12. It is better that physician focus on disease instead of pain & 2.91 & 1.44 \\
13. The use of pain medications may harm the immune system & 2.14 & 1.11 \\
14. Taking pain medications can make lose the control upon behavior & 4.28 & 1.56 \\
15. If pain medications are used with less pain they may not respond in the time of much pain & 2.32 & 1.19 \\
16. There is a risk of becoming addicted to pain medications & 3.97 & 1.24 \\
17. When I use the pain medications my body accustomed to it and the drugs lose their effect & 4.87 & 0.9 \\
18. Pain medications cause I'm not aware of what is happening in my body & 3.97 & 1.24 \\
19. Constipation caused by pain medications cannot be cured & 3.04 & 1.39 \\
20. Pain tolerance is easier to tolerate the side effects of pain medications & 3.95 & 1.39 \\
21. Analgesics relieve cancer pain & 2.69 \\
22. If the patient is talking about the pain that others think he is growler & 1.22 \\
23. Reports of pain may distract the physicians from treating disease & 2.67 & 1.01 \\
24. The physicians were bothered by listen about patients' pain & 2.63 \\
25. Pain medications will be hide the changes in patients' health & 1.07 \\
26. If pain medications used in the early stages of the disease their analgesic effect may be reduced in the & 3.28 & 0.68 \\
next times & 4.02 & 1.54 \\
27. If physicians are forced to treat pain they will not focus on patients' treatment & 3.26 \\
\hline SD = Standard deviation & 3.59 \\
\hline
\end{tabular}

treating disease and bothered them. Sixth, in three items $(15,17,26)$ participant reported that they moderately believed that if pain medications are used with less pain they may not respond in the time of much pain.

\section{Discussion}

The aim of this study was to investigate the nurses related barriers for control of cancer pain among Iranian nurses. To our knowledge this study is the first investigated this issue among Iranian nurses or nurses from other Middle Eastern countries.

The main result of present study is that Iranian nurses had a negative attitudes regarding pain control among cancer patients. This result is consistent with the results of previous studies. For example, the results of one study on Italian hospice nurses showed that these nurses have many misconceptions and negative attitudes towards pain management in advanced cancer patients (Bernardi et al., 2007). As another example the results of another study showed that physicians, nurses, and pharmacists from United States have many negative beliefs regarding pain control (Furstenberg et al., 1998).

The results of present study showed that many of nurses believed that pain medications have many uncontrollable complications. So, one main nurse-related barrier for control of cancer pain is misconception of nurses about side effects of pain medications. The results of previous systematic review showed that most frequently mentioned barriers for professionals were knowledge deficits and misconceptions regarding pain (Oldenmenger et al., 2009). Similarly, the results of another systematic review showed that the most prominent physician-related barriers for cancer pain management were insufficient physicians' knowledge about cancer pain management (Jacobsen et al., 2009). Also, the results of other study showed that fear about pain medications is one of most important barriers to cancer pain control as reported by home-health and hospice nurses and patients (RandallDavid et al., 2003).

The results of present study showed that participants believed that pain medications cannot really control cancer pain and reporting pain by patients indicates their weakness. These results indicate negative attitudes of participants about controlling cancer pain. Although, the results of some studies showed that nurses believed that the main barrier for controlling cancer pain is patient reluctance to report pain (Clarke et al., 1996). In addition, another study showed that nurses believed that pain medications are not so helpful in controlling cancer pain and cancer pain in many cases is inevitable (McMillan et al., 2000). So, these results are consistent with our results and approve that many nurse still have a lot of uncertainties about the positive effects of pain control medications. This finding is consistent with other studies that showed the quality of different aspect of daily living in cancer patients is low (Abbasnezhad et al., 2015; Aghdam et al., 2015; Faghani et al., 2015; Fathollahzade et al., 2015; Ghasempour et al., 2015; Tahory et al., 2016).

The results of this study have some clinical implication. 
These results shows that Iranian nurses have many misconception and negative beliefs about the efficacy of pain control medications and side effects of these drugs. So, there is a need for continuing education of theses nurses about cancer pain and its management. Especially, male nurses and nurses with less work experience should be a priority. Also, there is a need for change in curriculum of nursing education to include more courses about symptom management in oncology settings.

This study has some limitations. First, this study conducted in two province in northwest of Iran. So, generalizing its finding to other parts of Iran is difficult. Second, the sample size of this study was love and 49 nurses were participated. So, other studies in other parts of Iran or other Middle Eastern countries are needed.

\section{Acknowledgements}

This article is from Master of Science thesis in nursing submitted to Nursing and Midwifery faculty of Tabriz University of Medical Sciences. Thanks to all nurses who participate in these study.

\section{References}

Abbasnezhad M, Rahmani A, Ghahramanian A, et al (2015). Cancer care burden among primary family caregivers of iranian hematologic cancer patients. Asian Pac J Cancer Prev, 16, 5499-505.

Aghdam AM, Aghaei MH, Hassankhani H, et al (2015). Awareness and attitude of nurses in regard to providing hospice care. Asian Pac J Cancer Prev, 16, 6941-5.

Al Khalaileh M, Al Qadire M (2012). Barriers to cancer pain management: Jordanian nurses' perspectives. Int J Palliat Nurs, 18, 535-6.

Al Qadire M, Tubaishat A, Aljezawi MM (2013). Cancer pain in Jordan: prevalence and adequacy of treatment. Int J Palliat Nurs, 19, 125-30.

Andrew R, Derry S, Taylor RS, et al (2014). The costs and consequences of adequately managed chronic non-cancer pain and chronic neuropathic pain. Pain Pract, 14, 79-94.

Arslan D, Koca T, Akar E, et al (2014). Cancer pain prevalence and its management. Asian Pac J Cancer Prev, 15, 8557-62.

Aslan FE, Kayis A, Inanir I, et al (2011). Prevalence of cancer pain in outpatients registered to a cancer therapy center in Turkey. Asian Pac J Cancer Prev, 12, 1373-5.

Bernardi M, Catania G, Tridello G (2007). Knowledge and attitudes about cancer pain management: a national survey of Italian hospice nurses. Cancer Nurs, 30, E20-6.

Burton AW, Cleeland CS (2001). Cancer pain: progress since the WHO guidelines. Pain Pract, 1, 236-42.

Chang MC, Chang YC, Chiou JF, et al (2002). Overcoming patient-related barriers to cancer pain management for home care patients. A pilot study. Cancer Nurs, 25, 470-6.

Clarke EB, French B, Bilodeau ML, et al (1996). Pain management knowledge, attitudes and clinical practice: the impact of nurses' characteristics and education. J Pain Symptom Manage, 11, 18-31.

Dantzer R, Meagher MW, Cleeland CS (2012). Translational approaches to treatment-induced symptoms in cancer patients. Nat Rev Clin Oncol, 9, 414-26.

Deandrea S, Montanari M, Moja L, et al (2008). Prevalence of undertreatment in cancer pain. A review of published literature. Ann Oncol, 19, 1985-91.

Eftekhar Z, Mohaghegh MA, Yarandi F, et al (2007). Knowledge and attitudes of physicians in Iran with regard to chronic cancer pain. Asian Pac J Cancer Prev, 8, 383-6.

Faghani S, Mohammadian R, Rahmani A, et al (2015). Supportive Care Needs of Iranian Cancer Survivors and Relationships with Social Support. Asian Pac J Cancer Prev, 16, 6339-45.

Fathollahzade A, Rahmani A, Dadashzadeh A, et al (2015). Financial distress and its predicting factors among iranian cancer patients. Asian Pac J Cancer Prev, 16, 1621-5.

Fazeny B, Muhm M, Hauser I, et al (2000). Barriers in cancer pain management. Wien Klin Wochenschr, 112, 978-81.

Furstenberg CT, Ahles TA, Whedon MB, et al (1998). Knowledge and attitudes of health-care providers toward cancer pain management: a comparison of physicians, nurses, and pharmacists in the state of New Hampshire. $J$ Pain Symptom Manage, 15, 335-49.

Ghasempour M, Rahmani A, Davoodi A, et al (2015). Return to work and its relation to financial distress among Iranian cancer survivors. Asian Pac J Cancer Prev, 16, 2257-61.

Gunnarsdottir S, Donovan HS, Serlin RC, et al (2002). Patient-related barriers to pain management: the Barriers Questionnaire II (BQ-II). Pain, 99, 385-96.

Howell D, Butler L, Vincent L, et al (2000). Influencing nurses' knowledge, attitudes, and practice in cancer pain management. Cancer Nurs, 23, 55-63.

Jacobsen R, Liubarskiene Z, Moldrup C, et al (2009). Barriers to cancer pain management: a review of empirical research. Medicina (Kaunas), 45, 427-33.

Laugsand EA, Sprangers MA, Bjordal K, et al (2010). Health care providers underestimate symptom intensities of cancer patients: a multicenter European study. Health Qual Life Outcomes, 8, 104.

Macfarlane TV, Wirth T, Ranasinghe S, et al (2012). Head and neck cancer pain: systematic review of prevalence and associated factors. J Oral Maxillofac Res, 3.

Marcus DA (2011). Epidemiology of cancer pain. Curr Pain Headache Rep, 15, 231-4.

McMillan SC, Tittle M, Hagan S, et al (2000). Knowledge and attitudes of nurses in veterans hospitals about pain management in patients with cancer. Oncol Nurs Forum, 27, 1415-23.

Mishra S, Bhatnagar S, Chaudhary P, et al (2009). Breakthrough cancer pain: review of prevalence, characteristics and management. Indian J Palliat Care, 15, 14-8.

Oldenmenger WH, Sillevis Smitt PA, van Dooren S, et al (2009). A systematic review on barriers hindering adequate cancer pain management and interventions to reduce them: a critical appraisal. Eur J Cancer, 45, 1370-80.

Potter VT, Wiseman CE, Dunn SM, et al (2003). Patient barriers to optimal cancer pain control. Psychooncol, 12, 153-60.

Randall-David E, Wright J, Porterfield DS, et al (2003). Barriers to cancer pain management: home-health and hospice nurses and patients. Support Care Cancer, 11, 660-5.

Tahory H, Mohammadian R, Rahmani A, et al (2016). Viewpoints of family caregivers about posttraumatic growth in cancer patients. Asian Pac J Cancer Prev, 17, 755-8.

van den Beuken-van Everdingen MH, de Rijke JM, Kessels AG, et al (2007). Prevalence of pain in patients with cancer: a systematic review of the past 40 years. Ann Oncol, 18, 1437-49.

van der Eerden M, Csikos A, Busa C, et al (2014). Experiences of patients, family and professional caregivers with Integrated Palliative Care in Europe: protocol for an international, multicenter, prospective, mixed method study. BMC Palliat Care, 13, 52. 